\title{
Od czarów nad kołyską do magii językowej usieciowionej matki - ciągłość i zmienność charakteru magii języka matek
}

Zgodnie z definicją w Encyklopedii językoznawstwa ogólnego (1999, s. 352) magia językowa to ,posługiwanie się wyrażeniami języka w przekonaniu, że za ich pomocą oddziałuje się na rzeczywistość". Z identyfikacji, utożsamiania wyrazu z nazywaną przezeń rzeczą, właściwych myśleniu magicznemu, wypływa wiara w realną siłę sprawczą słowa (por. Walczak 1988, s. 54; Dąbrowska 1995, s. 3). Magia języka to nie tylko właściwość tradycyjnych kultur ludowych. Jak zauważa A. Chudzik, autorka monografii Mowne zachowania magiczne w ujęciu pragmatyczno-kognitywnym (2002) ${ }^{1}$, „w świecie szybkich zmian cywilizacyjnych [magia językowa - J.L.] przybiera dziś nową, być może bardzo ciekawą i zaskakującą postać" (Chudzik 2002, s. 31). Autorka widzi współcześnie magiczne zachowania mowne w domenach: zachowań grzecznościowych, wyrażeń ekspresywnych, rytuałów socjalizujących oraz w języku reklamy. Inni badacze piszący na temat dzisiejszych przejawów magii językowej wspominają, badając język reklamy, polityki czy — szerzej — dyskursu publicznego: „wystarczy zmienić nazwę, by zmieniła się sama rzecz” (Walczak 1988, s. 62), „rzeczywistość nie nazwana nie istnieje” (Dąbrowska 1995, s. 11), „magiczność w języku reklamy przejawia się i w tym, że słowa tu nie muszą oznaczać konkretnych rzeczy" (Zimny 1994, s. 3) (wystarczy uaktywnienie skojarzeń, co dodaje A. Dąbrowska (1995, s. 10)). Na obecność myślenia magicznego w dyskursie publicznym pośrednio wskazuje też J. Bralczyk (2003): „,nawet zdając sobie sprawę z tego, że teksty, intencjonalnie i nieadekwatnie opisując rzeczywistość mogą wypaczać nam jej obraz, skłonni jesteśmy nieraz przypisywać im funkcję kreacyjną, zaczynamy uważać, że to od nich zależy nie tylko sposób widzenia rzeczywistości, lecz także ona sama [...]

1 Tam też szerokie omówienie literatury przedmiotu. 
a nasze powodzenie wiążemy z myśleniem pozytywnym [...] coraz częściej zachowujemy się tak, jakbyśmy wierzyli w magiczny wpływ opisu rzeczywistości na jej kształt" (Bralczyk 2003, s. 118)2.

Idąc tropem A. Chudzik, przyjmuję, iż „magiczne” akty mowy to ukryte dyrektywy, a „cechą, która odróżnia je od innych obligatywnych aktów mowy, jest ich odbiorca — »istnienie obligowane «, które nie jest człowiekiem [...] przy czym - moc »obligowanego istnienia « tkwi często w samych słowach" (2002, s. 57). Podstawowe funkcje, jakie pełnią magiczne zachowania mowne, to chęć wpływania na rzeczywistość oraz, częściej nieuświadamiana, potrzeba zachowania równowagi psychicznej — inaczej: funkcja psychoterapeutyczna (Chudzik 2002, s. 43) ${ }^{3}$.

$\mathrm{W}$ niniejszym artykule interesuje mnie działanie słowem motywowane sytuacją frustracji, a wiążące się z (uświadamianym bądź nie) poczuciem sprawczej mocy języka - magii językowej. Jako takie, magiczne, interpretuję prośby i groźby oraz skargi i żale wyśpiewywane przez matki w ludowych kołysankach (powołując się na poczynione już w tym zakresie uwagi badaczy kołysanek) i jako taki, magiczny — tę hipotezę postaram się udowodnić — chcę widzieć społecznościowo budowany przez współczesnych rodziców (głównie matki) sieciowy magazyn o tytule: „Bachor. Bezradnik dla nieudacznych rodziców”4. Zestawiam te dwa obszary obserwacji w celu wykazania specyfiki dawnych i współczesnych uwarunkowań charakteru magicznych, w mojej interpretacji, zachowań mownych matek sfrustrowanych codziennością z dzieckiem. Priorytetowo traktuję rzeczywistość współczesną i możliwości (w perspektywie kulturowej i technologicznej), jakie ona daje. Po dawne kołysanki sięgam docelowo głównie dla zilustrowania granic możliwości kształtowania rzeczywistości zewnętrznej przez matki dawne.

Zastanawiając się nad kulturowymi uwarunkowaniami ciągłości i zmienności charakteru magiczności interesujących mnie tu zachowań mownych, zwracam uwagę na dwa podstawowe konteksty związane z kulturowym osadzeniem, po pierwsze, przedmiotu i podmiotu frustracji: dziecka i matki i, po drugie, do czego przywiązuję szczególną wagę - medium ekspresji. Mianowicie na zachowa-

${ }^{2}$ Wprawdzie wspominając o reklamie, A. Chudzik mówi o „niby-magii”, ponieważ, jej zdaniem, „W przypadku działań magicznych sprawcza moc słowa jest wpisana w językowy obraz świata nadawcy, w reklamie nadawca jest świadomy konwencjonalności mechanizmów magicznych i celowo wykorzystuje brak tej świadomości u nadawcy" (Chudzik 2002, s. 127). Odmiennego zdania, jak się wydaje, jest jednak B. Walczak, według którego nie jest istotne przekonanie nadawców o rzeczywistej sile sprawczej słowa — ,przecież i dawni czarownicy sami nie zawsze wierzyli w realną skuteczność swych zaklęć — wystarczała im skuteczność w społecznej świadomości” (Walczak 1988, s. 64).

${ }^{3} \mathrm{Na}$ funkcję psychoterapeutyczną zwracał uwagę J. Szafraniec w książce Magia, ryty, terapia (Szafraniec 1994, s. 86).

4 „Bachor” dostępny był od listopada 2011 roku do października 2013 roku pod adresem www.bachormagazyn.pl. Obecnie strona już nie istnieje. Część materiału została zebrana do połowy 2013 roku, część na podstawie kopii fragmentów serwisu obecnej na web.archive.org. 
nia językowe matek wpływają zarówno funkcjonujący w danym czasie stereotyp dziecka i dominujące wartości, które się za nim kryją, jak i konwencja ekspresji frustracji, wiążąca się ze stereotypem matki i jej zachowań językowych. Kontekst medium, z kolei, w myśl McLuhanowskiego stwierdzenia „medium is the message", każe uwzględnić właściwości technologii definiującej (Bolter 1990, s. 40; por. Skowronek 2013, s. 52) i ewolucję kultury w stronę „kultur(y) mediów” (por. Lisowska-Magdziarz 2008).

\section{Kołysanki ludowe}

Kołysanka „wywodzi się z pieśni ludowych, a ściślej — z jednej z odmian, jaką są pieśni rodzinne. Jest zatem tworem obrzędowo-magicznym, w którym ujawnia się odwieczny archetyp matki-piastunki" (Adamczykowa 2001, s. 111). W kołysankę jako piosenkę śpiewaną w celu uśpienia dziecka wbudowana była (i jest) intencja życzeniowa, przy czym nawoływanie dziecka do snu nasycone było dawniej zabiegami językowymi o działaniu magicznym. Przykładowo, zawarte w nich prośby i groźby interpretować można jako słowne rytuały stwarzające i ochraniające według typologii A. Engelking (1991). I tak w prośbach o pomoc w uśpieniu dziecka i opiekę można się dopatrzyć, jak przekonuje B. Stefaniak-Maślanka, „śladów myślenia magicznego, zgodnie z którym cała natura, a także wszelkie przedmioty mogą wpływać na los człowieka. Mieszczą się tu [m.in. J.L.] zwroty kierowane do kołyski oraz fragmenty wskazujące na postaci wraz z matką usypiające dziecko" (Stefaniak-Maślanka 2012b 1991, s. 164), takie jak kotki, ptaszki. W wielu kołysankach adresatem słów matki byli aniołowie, święci lub sam Bóg, co zbliża ową prośbę do modlitwy. „Prośby pełniły funkcję ochronną, ale mogły również wiązać się z próbą zapewnienia dziecku szczęśliwego życia. W tym celu w kołysankach ludowych pojawiały się także tworzone przez matki projekcje przyszłości (zgodnie z wiarą, że to, co wypowiedziane, może się urzeczywistnić (motyw typowy np. dla kołysanek żydowskich))" (Stefaniak-Maślanka 2012b, s. 166). Groźby pojawiające się w kołysankach miały strukturę ,jeśli nie zaśniesz, to (stanie się coś złego)”. Mogły dotyczyć kary cielesnej, jak i tego, że ktoś przyjdzie, połknie lub porwie nieposłuszne dziecko — „ktoś”, czyli południce, popielice, mamuny, czarownice, zmory itp., ale też Cygan czy wilk (nie nazywano jednak prawdziwych obiektów lęku, przypuszczalnie, w opinii B. Stefaniak-Maślanki, wiązało się to z tabu językowym, z wiarą, że słowo jest je w stanie przywołać). Dla dziecka groźby te były bardzo realne, co wynika

${ }^{5}$ O kołysankach i wierszach kołysankowych w kontekście pojawiających się w nich magicznych zabiegów i śladów myślenia magicznego pisze Beata Stefaniak-Maślanka (2012b), za którą referuję niektóre myśli (odnotowując szczegółowo ich miejsce). 
z ludowego przekonania, iż słowa matki wypowiedziane do dziecka się spełniają (Engelking 1991, s. 160).

Pragnę zwrócić uwagę, iż często w kołysankach ludowych postacią najważniejszą była (i jest) matka. Dla interpretacji materiału współczesnego, który poddaję oglądowi w drugiej części artykułu, konkretniej — dla wykazania wspólnej motywacji zachowań mownych matek — frustracji, istotne wydaje się, że nie zawsze jest ona pełną miłości opiekunką, zdarza się, że narzeka na dziecko, złości się, spieszy. „Przez długi czas (w niektórych kulturach do dziś) kołysanki stanowiły jedną z niewielu form pozwalających kobietom na swobodną wypowiedź i wyrażenie negatywnych emocji” (Stefaniak-Maślanka 2012b, s. 163). Taki wydźwięk mają, na gruncie polskich opracowań, słowa J. Cieślikowskiego odnoszące się do wyodrębnionej przez niego grupy „kołysanek-skarg”. Mówi on, iż: „matka śpiewająca kołysankę, szczególnie matka z ludu, w swym twardym, surowym i powściągliwym w gest czy słowo życiu tu, przed kolebką najmłodszego dziecka, znajdowała ulegalizowaną okazję dla wyrażenia w bardziej czy mniej usymbolizowanej formie własnej tęsknoty czy skargi" (Cieślikowski 1985, s. 75). Przykładowe takie kołysanki to:

Oj ziuziaj mi ziuziaj, ty podły bachorze, com ja cie nalazła, osiwając zboże.

Oj ziuziaj-ze, ziuziaj, choć na goły ziemi, mame mas przy sobie, tate diabli wzieni ${ }^{6}$.

Kołysz mi się kołysz, kolibecko z lipki,

a ja sobie pojdę, kiej mi grają skrzypki ${ }^{7}$.

A lulajze, lulaj, bo cię wrzucę w Dunaj,

z Dunaju na Wisłę, tam cię, Maryś, wyślę

Kołysankowe nawoływanie dziecka do snu było (i jest) wpływaniem słowem na rzeczywistość zewnętrzną — ma spowodować uśnięcie dziecka. Było (i jest) też działaniem w sferze emocji, powodowaniem zmiany w rzeczywistości psychicznej. Mianowicie, śpiewając kołysanki, matka „zapewnia[ła - J.L.] sobie i dziecku bezpieczeństwo i opiekę, ale już samo śpiewanie kołysanek, wyrażanie w nich lęku, bólu, złości, trudnych emocji, może przynieść jej ulgę i działać terapeutycznie" (Stefaniak-Maślanka 2012b, s. 163). Przemiany te zachodziły dzięki zabiegom językowym o działaniu magicznym, które zasadzały się na uznawanym przez nadawcę i odbiorcę obrazie świata. Albowiem „aby zrozumieć występujące w wypowiedziach magicznych wartościowanie należy je powiązać z całościo-

${ }^{6}$ Cyt. za: J. Milewska, Kolysanki z Ciechanowskiego, „Wisła” XV, 1901, s. 20 (podaję za: Cieślikowski 1985, s. 75).

7 Cyt. za: H. Biegeleisen Matka i dziecko w obrzędach, wierzeniach i zwyczajach ludu polskiego, Lwów 1927, s. 167 (podaję za: Cieślikowski 1985, s. 75).

8 Cyt. za: J. Kowalczykówna, wyb., Luli, luli..., Lublin 1998, s. 25-26 (podaję za: Stefaniak-Maślanka 2012a, s. 170). 
wym światopoglądem właściwym danej społeczności i danej kulturze" (Chudzik 2002, s. 78). W ludowej kulturze polskiej pozytywnie wartościowane były zjawiska należące do polskiej symboliki katolickiej. Symboliczne znaczenie w ludowych formułach magicznych mogły mieć zwierzęta, rośliny, miejsca, liczby — co widoczne jest $\mathrm{w}$ opisanych wyżej kołysankach, w których wymienione symbole są siłami opiekuńczymi i dobroczynnymi.

Współczesne kołysanki zdają się kolejnym narzędziem profesjonalizacji rodzicielstwa (por. Urbańska 2012) — moc ich oddziaływania leży w racjonalnym działaniu (por. Czubaszek 2012). Spotkamy też w sieci zapis kołysanek tworzonych na wzór przywołanych wyżej kołysanek-skarg, których funkcja psychoterapeutyczna zbliżona jest do dawniejszych piosenek tego typu, na co wskazują sami cytujący je autorzy. Przykładowo przywołam dwie kołysanki (pierwsza z „Komentarzy” zamieszczonych pod jednym z artykułów w numerze „Bachora” poświęconym snowi, druga z blogowych zapisków Joanny Woźniczko-Czeczott, mających swoje przedłużenie w postaci książki Macierzyństwo non fiction. Relacja z przewrotu domowego (2012)):

Potwora do wora a wór do śmieci

w ten sposób należy traktować dzieci (x 2).

z dopiskiem:

Tatuś mi tak śpiewał, toteż uznałam za wychowawcze;-).

J. Woźniczko-Czeczott przypomina kołysankę, którą jej mąż pamięta z dzieciństwa:

$\mathrm{Na}$ cmentarzu o północy błąkają się dusze

Nie płacz, nie płacz mój malutki i tak cię uduszę.

Uśnij, zaśnij, mój malutki, już jest wpół do drugiej,

tatuś właśnie zsiniał cały, ma dwa zęby długie.

$\mathrm{Na}$ cmentarzu o tej porze błąkają się duchy,

dzieciom, które jeszcze nie śpią wyrwą nogi z dupy.

Cytowane tu kołysanki pochodzą z sieciowych zapisów rodziców. Z relacji: matka/rodzic-dziecko, w której pełnią funkcję magiczną w obu wymiarach (i powodują zaśnięcie dziecka, i działają terapeutycznie na śpiewającego), przesuwają się w stronę: matka-adresat zbiorowy (społecznościowy?) czytający zapis elektroniczny. Na tym poziomie komunikacji ich funkcja się zmienia — stają się, jak się wydaje, ekspresją doświadczeń, częścią dyskursu tożsamościowego.

Mogą jednak nabrać mocy zmieniania rzeczywistości, kiedy stają się częścią większej całości - swego rodzaju makroznaku, intencjonalnie mającego dokonywać zmian w rzeczywistości zewnętrznej. Współcześnie bowiem zmienia się kontekst kulturowy zachowań językowych — zmianie ulegają i przejawy magii językowej, i skala jej działania. Możliwości językowego oddziaływania matek/ rodziców na rzeczywistość zewnętrzną — już nie tylko na dzieci — znacznie 
się powiększyły dzięki dostępowi do mediów. „Obecnie media można traktować jako szeroko otwartą »bramę«, platformę dla prezentacji najrozmaitszych sensów — także tych, które wcześniej funkcjonować musiały na obrzeżach. [...] dzięki mediom, najróżniejsze rodzaje aktywności semiotycznej mają swoich reprezentantów, swoje równorzędne miejsce we współczesnym pejzażu semiotycznym niezależnie od naszej oceny tego zjawiska" (Skowronek 2013, s. 46).

\section{II. „Bachor”}

\section{Intencje}

„Bachor. Bezradnik dla nieudacznych rodziców” redagowany był przez trzy mamy przy współudziale innych rodziców. Jak twierdzą same autorki, w swoim założeniu ${ }^{9}$ ma „spuszczać powietrze” (sformułowanie Katarzyny Nowakowskiej, jednej z redaktorek, w wywiadzie dla Polskiego Radia ${ }^{10}$ ). I dalej słyszymy: w „momencie, kiedy nie możemy udusić naszych dzieci, ani nawet byśmy nie chcieli tego zrobić, a wiemy, że bicie, wrzeszczenie to nie są dobre metody wychowawcze i nie chcemy tego stosować, więc kiedy ta para uszami nam już bije, kiedy już naprawdę jedyną alternatywą jest już zacisnąć zęby na klamce, to sobie piszemy jakiś taki tekst, trochę prowokacyjny, w którym sobie kreujemy taką alternatywną rzeczywistość, w której możemy się troszeczkę wyżyć i nic nas tam nie powstrzymuje". Chwilę dalej w wywiadzie Nowakowska rozwija jeszcze: „my sobie na naszym małym poletku uprawiamy jakąś tam partyzancką walkę o to, żeby można było czasami tak po prostu szczerze powiedzieć »dziecko mnie wkurza!« albo »chciałbym robić coś innego, a nie układać puzzle«". Ich zachowania językowe sytuują się, w mojej interpretacji, w dwu wymiarach działania: w pierwszym mają na celu dokonanie zmian $\mathrm{w}$ rzeczywistości psychicznej oczyszczenie, katharsis przez czarny humor (do tego odnosi się pierwszy cytowany fragment) ${ }^{11}$. Drugi poziom działania językiem, na którym pragnę skupić uwagę $\mathrm{w}$ dalszej części artykułu, interpretuję jako magiczne działanie mowne w sferze publicznej rzeczywistości społecznej (tu sytuuję drugą część wypowiedzi). Postaram się ten sąd uzasadnić. Najpierw jednak zaprezentuję sam magazyn.

\footnotetext{
${ }^{9}$ Intencje te zostały wyłożone w licznych paratekstach, ten podaję jako przykładowy.

10 Polskie Radio dla zagranicy, wywiad przeprowadzony z Katarzyną Nowakowską przez red. Przemysława Pawełka 8 sierpnia 2012.

11 Tym aspektem, ze względu na ograniczone ramy artykułu, nie zajmuję się tu szerzej; sądzę, że będzie on czytelny w kontekście zawartych w niniejszym tekście uwag (poświęcam mu osobny szkic: Legomska w druku).
} 


\section{Prezentacja materiału}

„Bachor” zachowuje temat i kompozycję poradników dla rodziców. Pragmatyczno-stylistyczne właściwości wzorca poradnika zostają uformowane à rebours (por. Ficek 2013, s. 163).

Sam podtytuł „bezradnik” jest odwróceniem intencji wpisanej w gatunek „poradnika”, wyraża niemoc. Projektowany odbiorca to „rodzic nieudaczny”, o którym czytamy w tytule i o którym niejednokrotnie w tekstach mówi się podobnymi słowami, np. poprzez bezpośredni zwrot „Kochani nieporadni” w zakładce „,bachor.mag.stopka”, fragmenty typu: „,zy może istnieć dla tak beznadziejnych rodziców (obecnych i przyszłych) jak Wy lepsza rekomendacja?” czy na zakończenie testu: „Teraz pewnie chcielibyście przeczytać, jakimi rodzicami jesteście. Moglibyśmy tu eufemistycznie owijać w bawełnę pitu pitu, a sprawa jest całkiem prosta - bez względu na to, których liter macie najwięcej - BEZNADZIEJNYMI! Sorry ${ }^{12 ” . ~ Z n a m i e n n y ~ j e s t ~ t u ~ t e z ̇ ~ s p o s o ́ b ~ k o n s t r u o w a n i a ~ t y t u ł o ́ w, ~ n p .: ~ „ D r z e ~}$ ryja? nic na to nie poradzisz”, „Depresja poporodowa? możesz z tego nie wyjść”, „Niejadek — sprawdź, kiedy umrze”. Zachowując formę właściwą poradnikom (problem - rozwiązanie), wyrażają pesymistyczne przekonanie o braku możliwości zmiany, braku wiary w nią.

Dziecko w badanych tekstach nazywane jest „bachorem” (sam tytuł), „bestią”, „potworem”, „gnojkiem”, „gówniarzem”, „pomiotem” — określenia te pojawiają się już w okładkowych zapowiedziach tekstów - dla przykładu: „Superporadnik bachora - Jak go nie zatłuc?” albo „Imię bestii — jak przywołać gnojka?” czy w nazwach akcji społecznych magazynu, np. „Zagoń potwora do roboty”. W opisach dominuje leksyka wartościująca negatywnie, najczęściej pospolityzmy, pojawiają się też, choć nie we wszystkich tekstach, wulgaryzmy. Przykładowo fragment testu: ,[...] 5. Zbliża się wycieczka, rada rodziców przysyła list z wytycznymi co zabrać, w co spakować i o której się zebrać. a. rada kogo? Masz na to wyjebane, twój bachor i tak nic nie zeżre, a jak zeżre to zarzyga, poza tym i tak się spóźnicie, więc nie obchodzi cię pora zbiórki. b. szukasz w panice WYMAGANEJ papierowej torebki na kanapki, a gdy nie znajdujesz pakujesz suchą bułę z serem mimowolnie pleśniowym w stronę $\mathrm{z}$ »Przeglądu Sportowego« c. zawijasz bachorowi czipsy, batona I kokakolę w foliową torbę, pakujesz wszystko do najcięższego plecaka i wypychasz gnoja z domu dwie godziny przed czasem zbiórki”.

W „Bachorze” parodiowane są różne, charakterystyczne dla poradników formy, m.in. quizy, w których prawie zawsze jedna z odpowiedzi do wyboru zawiera elementy makabry, por. przykładowe odpowiedzi „Berserker” w quizie „Jak się odszczekać bezdzietnemu”: „[...] Przegryzasz tętnicę szyjną pierwszej koleżance po prawej, zaś pierwszej z lewej wyrywasz kręgosłup. Reszta opanuje się sama. [...] Strzelasz laserowym promieniem z pępka, po czym wgryzasz się im w tętnice

12 Wszystkie cytaty z „Bachora” przytaczam w oryginalnym zapisie. 
szyjne, wyrywasz kręgosłupy i krzyczysz »K.O.!« [...] Odżałowujesz te sto parę złotych, kupujesz cały tort z dużą ilością śmietany, ale taki na biało, wsadzasz jej na głowę, a dopiero potem przegryzasz tętnicę i patrzysz jak się pięknie czerwona krew komponuje z białym kremem...". Podobnie jak w poradnikach ogłaszane są - tu: á rebours - akcje społeczne, np. wspomniana tu już „Zagoń potwora do roboty”, ale też m.in.: „Porzucać po ludzku”, „Front wyzwolenia cyca”. Oto fragment opisu ostatniej z wymienionych: „Cyc jest tematem drażliwym zawsze, a w kontekście bachora nawet bolesnym. $Z$ cycem same problemy: za duży, za mały, za twardy, za miękki [...] — ch...wy jednym słowem. I zawsze jakiś kretyn uraczy cię uwagą: ?ale balony?! [...] albo przeciwnie powie coś o wklęsłych cyckach i deskach (deską to można w ryj zarobić, głowonogu o inteligencji ujemnej)”. „Bachor” obśmiewa też różne mody panujące w wychowaniu, o których rozpisują się poradniki dla rodziców, np. „Jeśli twój bachor był dobrym ekobachorem: segregował śmieci, jadł nieprzetworzoną brukiew i nie marnował zasobów twojej energii, w nagrodę możesz mu kupić ekozabawkę. Z drewna lub wikliny. Dopuszczalny jest też papier i wełna z owiec szetlandzkich. Wykonana oczywiście ręcznie przez parę niewidomych norweskich trolli lub pochodząca ze specjalnych ekoupraw zabawek w południowej Francji. Naucz bachora odczuwać naturalną odrazę i pogardę wobec zabawek z plastiku. I ch..., że edukacyjne! Baw się kartoflanym puzzlem, gówniarzu, albo eko nazi front zrobi ci z dupy jesień średniowiecza!”.

Trzeba uzupełnić przytoczoną charakterystykę „Bachora” o stwierdzenie, iż działanie językiem jest spójne z kodowaniem niewerbalnym. Przedstawienia obrazowe na okładkach to zdjęcia dzieci płaczących, krzyczących, z wydzielinami z nosa. U góry strony internetowej zamieszczone są schematyczne rysunki głów dzieci, które również płaczą i krzyczą. Cała strona zaś ma czarne tło.

\section{„Bachor” jako działanie słowem w sferze rzeczywistości zewnętrznej: blokowanie języka sukcesu}

Na płaszczyźnie działania słowem na rzeczywistość zewnętrzną interpretuję „Bachora” jako „blokowanie języka”"13 , reakcję na bardzo silnie obecną we współczesności kulturę sukcesu z właściwym jej językiem. Trzeba tu wspomnieć, iż, w odniesieniu do matek, język sukcesu sięga po wzór matki Polki do bazy kulturowej Polaków ${ }^{14}$. Lektura tekstów dyskursu tożsamościowego rodziców

13 „Blokowanie języka” jest określeniem M. Wolny-Peirs (2005, s. 85-88), ukutym w analogii do funkcjonującego określenia „blokowanie kultury” (konsumpcjonizm), a odnoszonego do działań ruchu antyglobalistów.

14 Jeśli sięgnąć do typologii języka publicznego J. Bralczyka i J. Wasilewskiego, trzeba by uznać model matki Polki za właściwy „źródłowo” językowi narodowemu. Jednak między wyszczególnionymi przez nich odmianami języka istnieją „zamierzone przez mówiących przeploty, czyli wzajemne relacje i zapożyczenia" (Bralczyk, Wasilewski 2008, s. 285). 
z nurtu non fiction, do którego włączam i „Bachora”, pozwala mi jednak przypuszczać, że głównym kanałem, którym dociera ów model do wielu rodziców, jest szeroko rozumiany język sukcesu - to reklamowe i poradnikowe obrazy wskazywane są w wywiadach z twórcami „Bachora” czy innych paratekstach wokół tego magazynu.

Kultura i język sukcesu zostały szeroko opisane, dość tu wspomnieć, że język sukcesu realizuje się w sztandarowej dla tej kultury formie poradników właśnie. U ich podstaw leżą: ideologia pozytywnego myślenia oraz teoria pomocy samemu sobie (self-help) (Wolny-Peirs 2005), w które ostrze „Bachora” jest wyraźnie skierowane. Obie koncepcje kładą nacisk na „wiarę w to, że dzięki odpowiedniemu formułowaniu myśli i planów można odnieść sukces" (Wolny-Peirs 2005, s. 155), a „wyrażanie wątpliwości czy poczucia winy może na mówiącego ściągnąć nieprzyjemne konsekwencje i zablokować jego dostęp do sukcesu" (Wolny-Peirs 2005, s. 76). W dyskursie tym rzeczywistość kreowana to rzeczywistość marzeń realnych. Magiczne myślenie odzwierciedla się na poziomie języka w programowaniu słów (tu wystarczy przywołać koncepcję NLP) - J. Bralczyk i J. Wasilewski użytkowników tego języka nazywają „optymistycznymi hipnotyzerami” (2008, s. 278). W efekcie przestrzeń mentalna członków dzisiejszych społeczeństw się kurczy, przez „daleko posuniętą propozycję skorygowania języka, pozbycia się jego naturalnych elementów [negatywnych i neutralnych - J.L.] i zastąpienie ich innymi" (Wolny-Peirs 2005, s. 76).

Mianowicie język poradników dla rodziców wyznacza granice myślenia i mówienia o dzieciach oraz o rodzicach. „Autorzy opisują [w poradnikach J.L.] pewien świat idealny, świat bez zmartwień, bez »klęsk ostatecznych «, świat »bezkresnych sukcesów « [...] entuzjazm” (Wolny-Peirs 2005, s. 161). Słownictwo służące temu wydaje się raczej ubogie. Wiele słów występuje w stałych połączeniach. Z moich obserwacji poradników dla rodziców wynika, że dziecko bardzo często pojawia się w nich w otoczeniu metafor zasadzających się na domenach źródłowych: ciepło, słodko, jasno, kolorowo/różowo. Poradnikowe matki (gdzie „poradnikowe” znaczy i prezentowane w poradnikach, i stworzone przez poradniki, istniejace $w$ realnym świecie) zobligowane są do afirmacji pozytywnych uczuć — ta jest niezbędna i w pewnym sensie przymusowa, gdyż we współczesnym dyskursie poradnikowym/wychowawczym „miłość macierzyńska czy emocje prezentowane są jako swoiste narzędzia do produkowania konkretnych cech osobowości" (tak o tym pisze S. Urbańska (2012, s. 66)). Emocje traktowane w nim są jako „swoista kondycja matki, mająca w sobie pewien sprawczy potencjał [...]. Prawidłowy stan emocjonalny matki jest traktowany jako racjonalne działanie wychowawcze samo w sobie" (Urbańska 2009).

Obserwacja licznych, m.in. zamieszczanych w sieci, tekstów rodziców ujawnia, że ci zahipnotyzowani optymizmem reklamowo-poradnikowego przesłania/świata w zderzeniu go z inną rzeczywistością niż przedstawiana w reklamach czy poradnikach przeżyli szok (podobny rozczarowaniu, kiedy reklamowany produkt okazał się 
inny niż w reklamie?), a winą za swoją frustrację obarczają kulturę sukcesu. Co istotne - akcentują w niej udział języka. Przytoczę tu jedną z głośniejszych wypowiedzi, głośniejszych pewnie dlatego, że wyszła z ust celebrytki, Agnieszki Chylińskiej: „Macierzyństwo to ściema! Wiem to na pewno! Poradniki, gazetki, reklamy pieluch nawet: wszyscy kłamią! [...]. Nigdzie nie przeczytałam o tym, że dziecko drze gębę. Znalazłam wzmianki o tym, że kwili, płacze, marudzi, gaworzy"15. W kontekście tych uwag można uznać „Bachora”, jak zapowiedziałam, za przejaw „blokowania języka" (sukcesu) czy, kontynuując trop M. Wolny-Peirs, Orwellowskiej „myślozbrodni” ${ }^{\text {. }}$. Myślozbrodnia czy blokowanie języka sukcesu odbywa się poprzez werbalizację/przyznawanie się do nieskuteczności i wyrażanie frustracji. „Bachor" uobecnia rodzica nieporadnego, agresywnego. Uobecnia tym silniej, że frustracja, nieskuteczność, moim zdaniem tak samo jak sukces (por. Wolny-Peirs 2005, s. 28,49 ), istnieją w wymiarze relacyjnym — ,jest to coś, o czym możemy komuś powiedzieć, bądź co może być o nas powiedziane" (Wolny-Peirs 2005, s. 28). Wyrażanie frustracji uobecnia ją, urzeczywistnia. Wyrażanie agresji uobecnia agresję.

Takie blokowanie możliwe jest w kulturze uczestnictwa, a ta, z kolei, budowana jest dzięki technologii definiującej. Matka dawna słowem tworzyć mogła tylko zewnętrzną rzeczywistość „najbliższą”, prywatną (usypiała dziecko), matka współczesna, przed którą otwierają się bramyt ekspresji w postaci mediów, działa na publiczną, społeczną rzeczywistość zewnęrzną — współtworzy ją. Mechanizm magii języka w komunikacji medialnej wspierany i potęgowany jest równaniem mediów dokonywanym przez ich odbiorców: media = prawdziwe życie (Reeves, Nass 2000, s. 15; zob. też omówienie tej teorii w Griffin 2003, s. 406-419). Innymi słowy: równanie mediów wspiera moc właściwego magicznym zachowaniom mownym „istnienia obligowanego”, moc, co powiedziałam na wstępie, tkwiącą często w samych słowach ${ }^{17}$.

Mianowicie, w mojej interpretacji, można spojrzeć na „Bachora”: jako na makroznak, odpowiedź na makroznaki skutecznego rodzica sukcesu, jakim są reklamy i poradniki. Intencje takie, w moim odczytaniu, werbalizują sami autorzy magazynu. W przywoływanym już wywiadzie radiowym Katarzyna Nowakowska mówi: „my jesteśmy na innej płaszczyźnie niż, nie wiem, magazyny parentingowe, chociaż my się z nich bezczelnie wyśmiewamy i tyle". W kolejnym wywiadzie (dla programu „Pod lupą” radiowej „Czwórki”, zatytułowanym Bobas vs. Bachor

15 Są to słowa A. Chylińskiej z felietonu Macierzyństwo to ściema zamieszczonego w „Machinie" (Chylińska 2006).

16 Określenie „myślozbrodnia” użyte zostało przez M. Wolny-Peirs w charakterystyce języka sukcesu - w języku sukcesu jest nią wyrażanie wątpliwości, niepokoju, zniechęcenia (2005, s. 77) — a pochodzi z Roku 1984 G. Orwella, dokładniej z rozmyślań filologa Syme'a redagującego słownik nowomowy (ich fragment: „W końcu doprowadzimy do tego, że myślozbrodnia stanie się fizycznie niemożliwa, gdyż zabraknie słów, żeby ją popełnić” (Orwell 1993, s. 57)).

${ }^{17}$ Myślę, że można twierdzić, iż współczesne przejawy magii języka w reklamie, polityce czy dyskursie publicznym mają moc kreowania rzeczywistości dzięki, w pewnym stopniu przynajmniej, medium przekazu. 
(13 stycznia 2012)) redaktor prowadzący tak podsumowuje wypowiedź zaproszonej do rozmowy Dominiki Więcławek, innej z twórczyń magazynu: „»Bachor« to tak naprawdę pastisz wyśmiewający medialne kreacje rodzicielstwa idealnego". Podobne są głosy czytelników i komentatorów — np. A. Graff w felietonie poświęconym „Bachorowi” (zamieszczonym prowokacyjnie w jednym z typowych czasopism-poradników dla kobiet — w wydawanym przez Agorę „Dziecku”) pisze: ,»Bachor« to podziemie, opozycja, partyzantka. To samizdat dla tych, którzy [...] mają po dziurki w nosie rodzicielskiej propagandy sukcesu" (3 czerwca 2014). W świetle tych słów (i innych wypowiedzi autorów) można stwierdzić, że agresja językowa obecna w „Bachorze” nie jest, w analizowanym tu wymiarze zachowania $^{18}$, wymierzona w dziecko, jak sądzę, a w owe makroznaki. Ma je, na zasadzie opozycji, blokować. Rzeczywistość nienazwana nie istnieje — trzeba więc ją ponazywać w mediach - uobecnić, wykorzystując przekonanie odbiorców mediów o rzeczywistej sile sprawczej słowa. Skoro poradniki jako teksty sukcesu tworza/ powołują idealnych rodziców, teksty takie jak „Bachor” uobecniać mają, w mojej interpretacji intencji nadawców, tych nieidealnych/nieporadnych. Oczywiście, siła oddziaływania „Bachora” jest nieporównywalnie mniejsza niż popularnych poradników czy egalitarnych reklam. Do tego dochodzi rozwarstwiony odbiór. Intencje autorów, w tym komizm „Bachora”, zostały przez jednych odczytane, przez innych nie ${ }^{19}$ - co wiąże się z faktem współwystępowania wielu zróżnicowanych wspólnot dyskursu/wspólnot interpretacyjnych ${ }^{20}$, szczególnie w dyskursie internetowym. Tym samym wartościom różne wspólnoty przypisują odmienne priorytety — to, co pożądane przez jednych (realizm niepowodujący frustracji), rodzi obawy u innych (por. uwagi o psychicznych pułapkach werbalizacji niezadowolenia w: Wojciszke, Baryła 2005). Dla wspólnoty dyskursu/interpretacyjnej „Bachora”, która relatywizuje tradycyjnie przyjęte wartości do własnych potrzeb i doświadczeń, uobecnienie rodziców nieporadnych jest pożądane.

\section{$* * *$}

I dawniej, i dziś w sytuacji frustracji związanej z dzieckiem matki sięgały po słowo. Żeby poradzić sobie ze złością, bólem, emocjami wywołanymi trudem

18 W sferze działania językiem na rzeczywistość wewnętrzną rzecz wygląda jeszcze inaczej — choć i tam intencjonalnie agresja ma wymiar symboliczny (por. Legomska w druku).

19 Bazą dla sądów dotyczących interpretacji odbiorców czynię komentujące go wypowiedzi pod samymi artykułami („,Komentarze”), uwagi rozproszone na różnych forach internetowych, artykuły w innych tytułach. Szerzej rozwarstwienie odbioru opisuję w tekście (Nie)stosownie (nie)dostowni rodzice. Czarny humor a konwencja mówienia o dziecku: intencje a odbiór (Legomska w druku).

${ }^{20}$ Odwołuję się do konceptu wspólnoty dyskursu za teorią R. Scollona i S.W. Scollon (1995) oraz pojęcia wspólnoty interpretacyjnej (Fish 2002) (por. ich omówienie jako nowych form społeczności wyrażających trwałe związki komunikacyjne w: Skowronek 2013). 
wiążącym się z codziennością z dzieckiem, jego zachowaniem, jego obecnością, też: trudem wypełnienia społecznych oczekiwań dotyczących realizacji swojej roli, wykorzystywały magiczne zachowania mowne, działając zarówno w wymiarze rzeczywistości wewnętrznej, psychicznej, jak i zewnętrznej. Wyrażanie złych emocji w kołysance przynosiło dawnym matkom ulgę i działało terapeutycznie, podobnie jak osiągane przez czarny humor katharsis piszących współcześnie w „Bachorze”. W wymiarze zewnętrznym kołysanka miała uśpić dziecko, „Bachor” ma zaś blokować kulturę sukcesu, w której jest miejsce tylko dla rodziców „skutecznych”, afirmujących pozytywne uczucia, przez wprowadzenie w rzeczywistość — poprzez słowo, słowo w mediach — rodziców nieporadnych, sfrustrowanych, przepełnionych negatywnymi emocjami.

Zwalniam się od odpowiedzi na pytanie, czy dobrze, że taka rzeczywistość jest pożądana.

\section{Bibliografia}

Adamczykowa Z. (2001), Kołysanka - poezja wczesnego dzieciństwa, [w:] eadem, Literatura dla dzieci. Funkcje, kategorie, gatunki, Warszawa.

Bolter J. (1990), Człowiek Turinga. Kultura Zachodu w wieku komputera, Warszawa.

Bralczyk J. (2003), O języku polskiej polityki lat osiemdziesiatych i dziewięćdziesiatych, Warszawa. Bralczyk J., Wasilewski J. (2008), Polskie języki publiczne, [w:] Polska polityka językowa w Unii Europejskiej, Katowice.

Chudzik A. (2002), Mowne zachowania magiczne w ujęciu pragmatyczno-kognitywnym, Kraków.

Chylińska A. (2006), Macierzyństwo to ściema, „Machina”, nr 4.

Cieślikowski (1985), Wielka zabawa, Wrocław.

Czubaszek M. (2012), Od magii językowej do racjonalizmu — rzecz o motywacji tabu językowego, [w:] Ruch w języku, język w ruchu, red. K. Lisczyk-Kubina, M. Mociołek, Katowice.

Dąbrowska A. (1995), Język magii - magia języka, „Literatura Ludowa”, nr 1.

Encyklopedia językoznawstwa ogólnego (1999), red. K. Polański, Wrocław.

Engelking A. (1991), Magiczna moc słowa w polskiej kulturze ludowej, „Język a Kultura” 1, red. J. Anusiewicz, J. Bartmiński, Wrocław.

Ficek E. (2013), Poradnik. Model gatunkowy i jego tekstowe aktualizacje, Katowice.

Fish S. (2002), Interpretacja, retoryka, polityka. Eseje wybrane, Kraków.

Griffin E. (2003), Podstawy komunikacji społecznej, Gdańsk.

Grzegorczykowa R. (1991), Problem funkcji języka i tekstu w świetle teorii aktów mowy, „Język a Kultura" 4, red. J. Bartmiński, R. Grzegorczykowa, Wrocław.

Legomska J. (w druku), (Nie)stosownie (nie)dostowni rodzice. Czarny humor a konwencja mówienia o dziecku: intencje a odbiór (seria: „Conversatoria Linguistica. Międzynarodowy Rocznik Naukowy").

Lisowska-Magdziarz M. (2008), Media nasze powszednie. Środki komunikowania masowego i szerokie paradygmaty medialne $w$ życiu codziennym Polaków u progu XXI wieku, Kraków.

Orwell G. (1993), Rok 1984, Warszawa.

Reeves B., Nass C. (2000), Media i ludzie, Warszawa.

Scollon R., Scollon S.W. (1995), Intercultural Communication. A Discourse Approach, Oxford.

Skowronek B. (2013), Mediolingwistyka. Wprowadzenie, Kraków. 
Stefaniak-Maślanka B. (2012a), Nad kolebka czy nad grobem? Opozycja życia i śmierci a zwiazki kołysanki z formami twórczości żałobnej, „Linguarum Silva 1. Opozycja - Przeciwieństwo — Kontrast w Języku i w Tekście", Katowice.

Stefaniak-Maślanka B. (2012b), Czary nad kołyska. Magia słowa w kołysance ludowej i lirycznym wierszu kołysankowym, „Poznańskie Studia Slawistyczne”, nr 3.

Szafraniec J. (1994), Magia, ryty, terapia, Warszawa.

Urbańska S. (2009), Profesjonalizacja macierzyństwa jako proces odpodmiotowienia matki. Analiza dyskursów poradnika „Twoje Dziecko” z 2003 i 1975 roku, [w:] Kobiety. Feminizm. Demokracja. Wybrane zagadnienia z seminarium IFiS PAN z lat 2001-2009, red. B. Budrowska, Warszawa.

Urbańska S. (2012), Naturalna troska o ciało i moralność versus profesjonalna produkcja osobowości. Konstruowanie modelu człowieka $w$ dyskursach macierzyńskich $w$ latach 70. (PRL) i na poczatku XX w., [w:] Pożegnanie z Matka Polką? Dyskursy, praktyki i reprezentacje macierzyństwa we wspótczesnej Polsce, red. R.E. Hryciuk, E. Korolczuk, Warszawa.

Walczak B. (1988), Magia językowa dawniej i dziś, [w:] Język zwierciadtem kultury, czyli nasza codzienna polszczyzna, red. H. Zgółkowa, Poznań.

Wojciszke B., Baryła W. (2005), Kultura narzekania, czyli o psychicznych pułapkach ekspresji niezadowolenia, [w:] Jak Polacy wygrywaja, jak Polacy przegrywaja, red. M. Drogosz, Gdańsk.

Wolny-Peirs M. (2005), Język sukcesu we wspótczesnej komunikacji publicznej, Warszawa.

Zimny R. (1994), Reklamowa nowomowa, „Aida”.

\section{From spells over the cradle to linguistic magic of a networked mother - continuity and change of the nature of mothers' language magic}

\section{Summary}

The essay draws attention to the fact that, since the old days, in the case of frustration connected with the child mothers have reached out for words, they have used words to affect both internal, psychic reality and the external one. Magical acts by means of language are based on the world image shared by the sender and the recipient. Polish folk culture positively valued phenomena referring to Polish Catholic symbols, therefore these symbols constitute protective and benevolent powers evoked in folk lullabies. The author suggests looking at contemporary linguistic activities performed by mothers frustrated with staying with the child, which activities are presented in the analysed website magazine Bachor as activities which also make use of the language magic. According to the author, the difference lies in changing the cultural context of linguistic behaviour and associating them in particular with the defining technology. In contemporary mediatised society the power of "obligatory existence", which was characteristic of magical speech activities, supports and intensifies the equation of media by recipients. Therefore, the author sees Bachor as the act of blocking the language of success which makes room only for parents who are "effective" and affirm positive feelings by introducing into reality — by means of words, words in media - incapable, frustrated parents who are full of negative feelings. The subject is discussed in a descriptive and not in an evaluative way.

Keywords: language magic, mothers' language, mediated communication 